Document downloaded from:

http://hdl.handle.net/10251/82256

This paper must be cited as:

Escrivá-Escrivá, G.; Roldán Porta, C.; De Jong, ECW. (2016). Nuisance tripping of residual current circuit breakers in circuits supplying electronic loads. Electric Power Systems Research. 131:139-146. doi:10.1016/j.epsr.2015.10.012

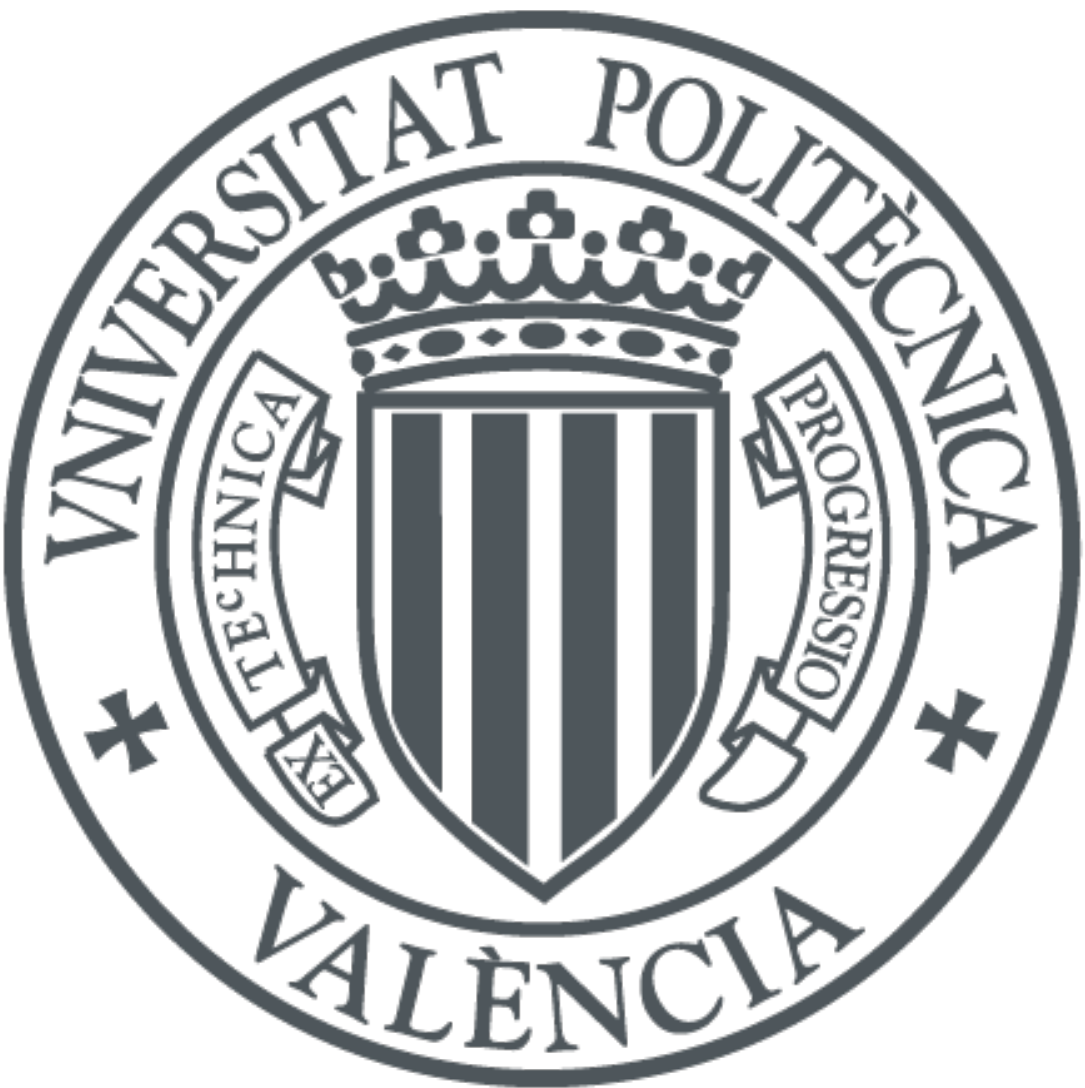

The final publication is available at

http://doi.org/10.1016/j.epsr.2015.10.012

Copyright Elsevier

Additional Information 


\title{
Nuisance Tripping of Residual Current Circuit Breakers in Circuits Supplying Electronic Loads
}

\author{
Guillermo Escrivá-Escrivá $\left({ }^{a}\right)\left({ }^{1}\right)$, Carlos Roldán Porta $\left({ }^{a}\right)$, E. C. W. de Jong $\left({ }^{b}\right)$
}

${ }^{\left({ }^{a}\right)}$ Institute for Energy Engineering, Universitat Politècnica de València, Camino de Vera, s/n, edificio 8E, escalera F, $2^{\text {a }}$ planta, 46022 Valencia, Spain

( $\left.{ }^{b}\right)$ DNV KEMA (Flex Power Grid Lab), Utrechtseweg 310, 6812AR Arnhem, the Netherlands

\begin{abstract}
Residual current circuit breakers (RCCBs) are often used to provide protection against indirect contacts in a grounded electrical installation. However, there are situations where the use of RCCBs presents certain problems. In circuits that feed electronic loads RCCBs often cause nuisance tripping. This article discusses the reasons why RCCBs trip in this type of circuit based on a previous case studied by the authors at 'La Fe' hospital in Valencia (Spain) and several tests performed in a power flexible laboratory. A theoretical circuit used to explain the phenomena is also presented.
\end{abstract}

Keywords: residual current circuit breaker, electronic loads, nuisance tripping, power quality.

\section{Introduction}

Nuisance tripping of residual current circuit breakers (RCCB) is often related to the presence of electronic loads, especially computers [1]. In some facilities, a common solution is to install immunised residual current circuit breakers (known as SI RCCBs following the commercial acronym for an improved type A RCCB - such those as manufactured by Schneider Electric). However, SI RCCBs are much more expensive than type A or AC standard residual current circuit breakers (A RCCBs or AC RCCBs).

Among the possible causes of random tripping, the presence of harmonic currents is often cited [2-7]. Recently, an interesting work [1] analysed the influence of harmonics on the value of

\footnotetext{
${ }^{1}$ Corresponding author. Tel.: +34 963879 240; fax: +34 963877 272. Email address: guieses@die.upv.es (G. Escrivá-Escrivá).
} 
the current that produces RCCB tripping. The influence of the time constant of an aperiodic current following an earth fault and the response of RCCBs to current pulses were also analysed $[2,8]$.

In currents with the presence of low-order harmonics, the minimum tripping current varies with harmonic content, as well as the phase angle of the harmonic component [1, 2]. RCCB tripping is primarily determined by the peak value of the current. Low-order harmonic components with angles that increase the peak value of the current facilitate RCCB tripping. In contrast, a desensitization of the RCCB is produced by the presence of high-order harmonics and the minimum tripping current generally increases with increasing harmonic frequency [1].

Low-order harmonics with small values can vary the value of the leakage current that forces the RCCB trips. However, this change is small and it is very improbable that it can explain the tripping of an AC RCCB. Moreover, higher order harmonics (frequencies up $1 \mathrm{kHz}$ ), or the fast transient connection or disconnection of some devices, rarely causes RCCB tripping [1, 2].

Thus, a current containing a high component of harmonics, as in circuits that feed electronic loads is not a cause of nuisance tripping. However, this type of circuit often suffers this problem. An explanation is presented in this paper.

In computer rooms RCCBs sometimes trip when the computers are running, and even when they are turned off. Therefore, the type of load present in a circuit should be considered because the load may increase the transient current, raising the neutral-earth voltages and leakage currents, and so increasing the frequency of trip events.

This article presents an investigation into the causes of RCCB nuisance tripping in circuits supplying electronic loads. Section 2 summarises the detected phenomena in a previous work at 'La Fe' hospital. Test results obtained in a laboratory with circuits feeding computers are discussed in Section 3. Section 4 details a theoretical circuit that explains the detected phenomena. Finally, some conclusions are drawn in Section 5.

\section{Detected phenomena in a previous work}

The detected phenomena in a facility with RCCB nuisance tripping was analysed by the authors in a previous work [1]. The nuisance tripping occurred in a large hospital which became operational in February 2011. During the first days of use there were many RCCB incidents. Given the need to find an urgent solution, maintenance staff began replacing AC RCCBs by SI 
RCCBs and the number of trips was reduced to a normal number in one or two days. More than 2000 RCCBs were replaced at a significant cost. After the devices were replaced, the authors were asked to investigate the cause of the problem.

The presence of strong disturbances in the grid voltage waveforms were detected after using a power quality analyzer (PQA) to record transients. Peak value increments (of up to 30 $\%$ of the nominal amplitude) and deformations (0.5 - 2 ms duration) in voltage waveforms in the three phases in the feeder were detected. It appeared that these disturbances caused the high current discharges that sometimes caused the RCCBs to trip.

Two electrical points were measured, firstly a circuit feeding nine rooms on a floor (circuit A), and secondly, a circuit feeding the main panel of the seventh floor of one of the blocks of the analysed hospital (circuit B).

Fig. 1 shows voltage waveforms and Fig. 2 shows currents obtained during an RCCB tripping event using the PQA in circuit $A$. When the trip occurs the voltage of phase $B$ falls to zero due to the measuring circuit used on the site [1]. The fault caused a peak in the currents (Fig. 2).

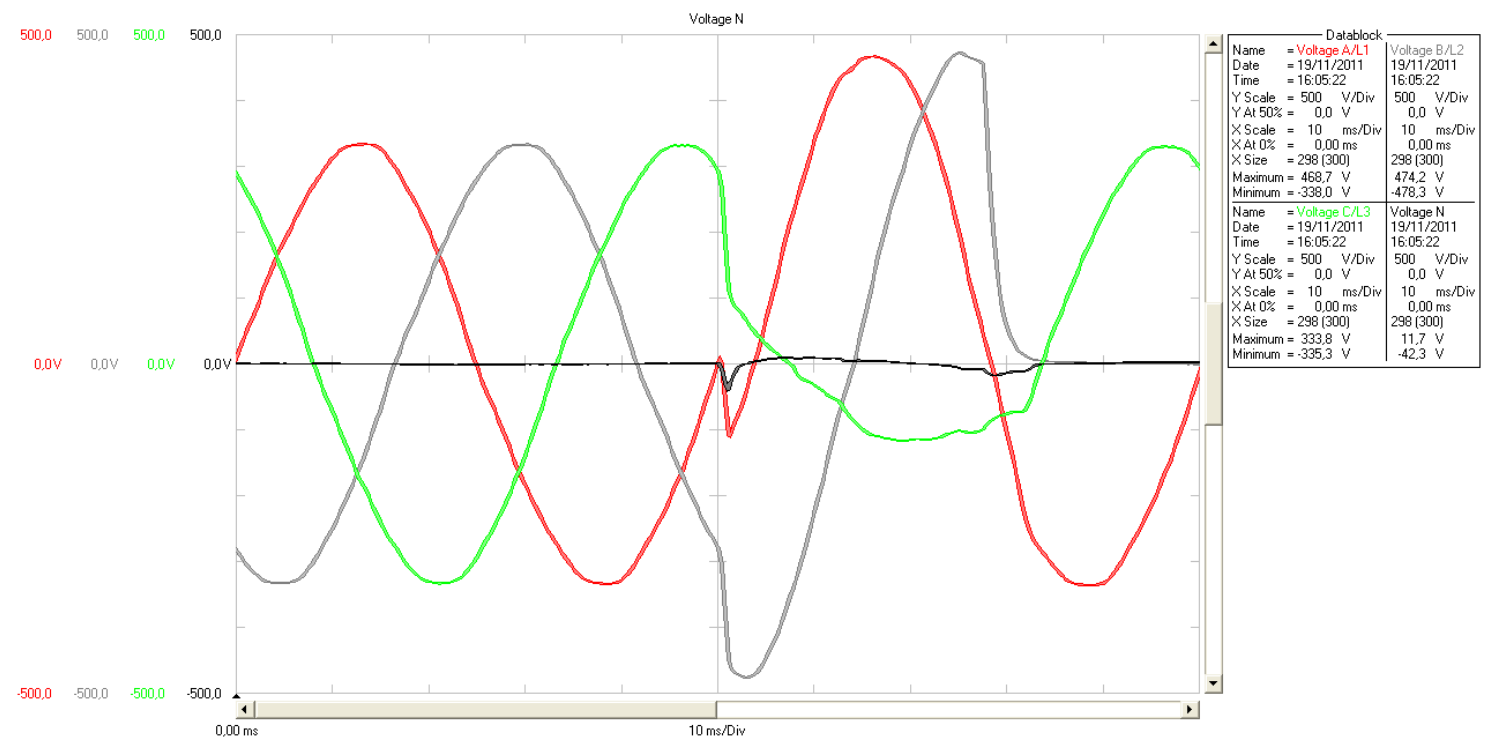

Fig. 1. Disturbance in the voltages produced during an RCCB tripping event on the 19/11/2011 at $4.05 \mathrm{pm}$ in circuit $A$. 


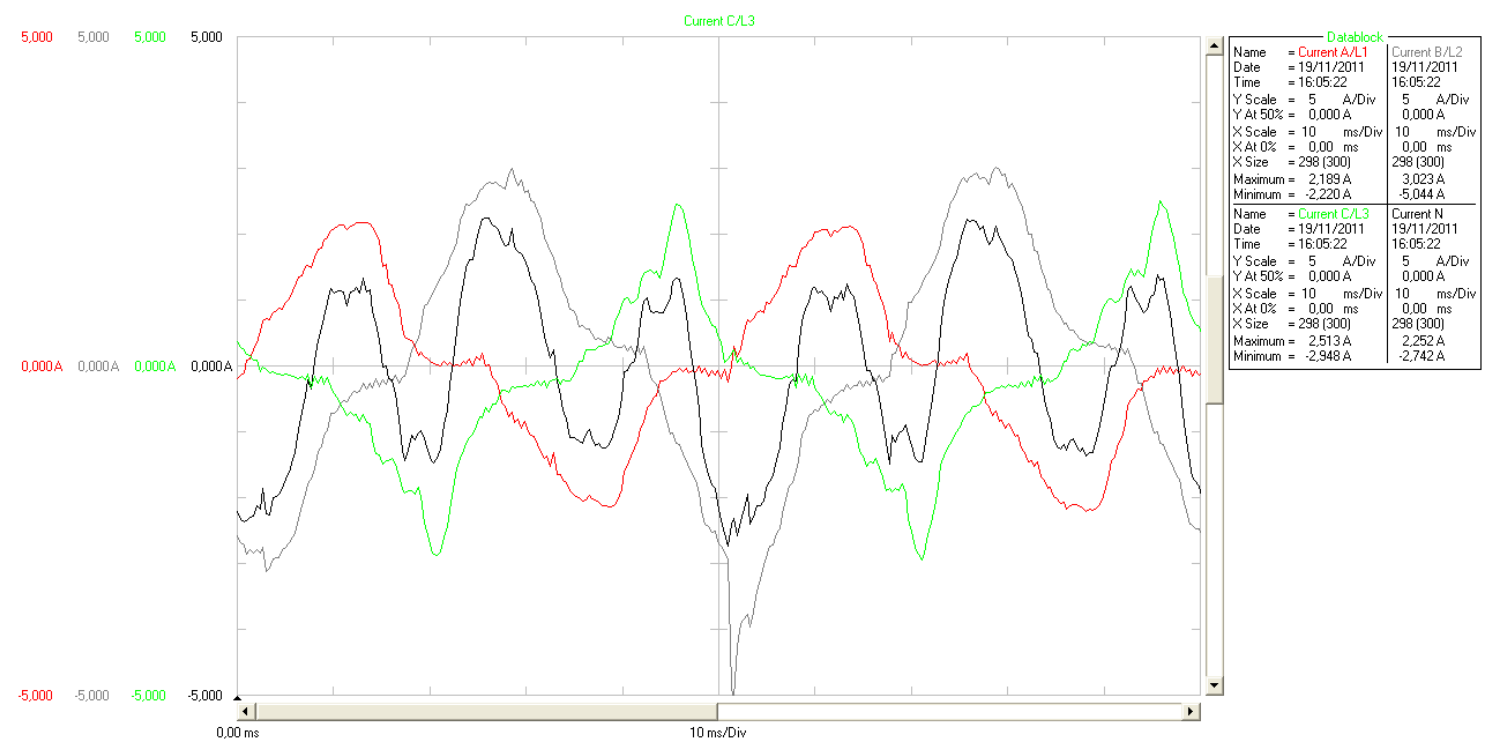

Fig. 2. Disturbance in the currents produced during an RCCB tripping event on the 19/11/2011 at $4.05 \mathrm{pm}$ in circuit $\mathrm{A}$.

Fig. 3 shows the leakage current calculated using the values of currents in the event shown in Fig. 2. Values of the leakage current are higher than $2 \mathrm{~A}$ and this clearly explains why a 30 mA AC RCCB tripped.

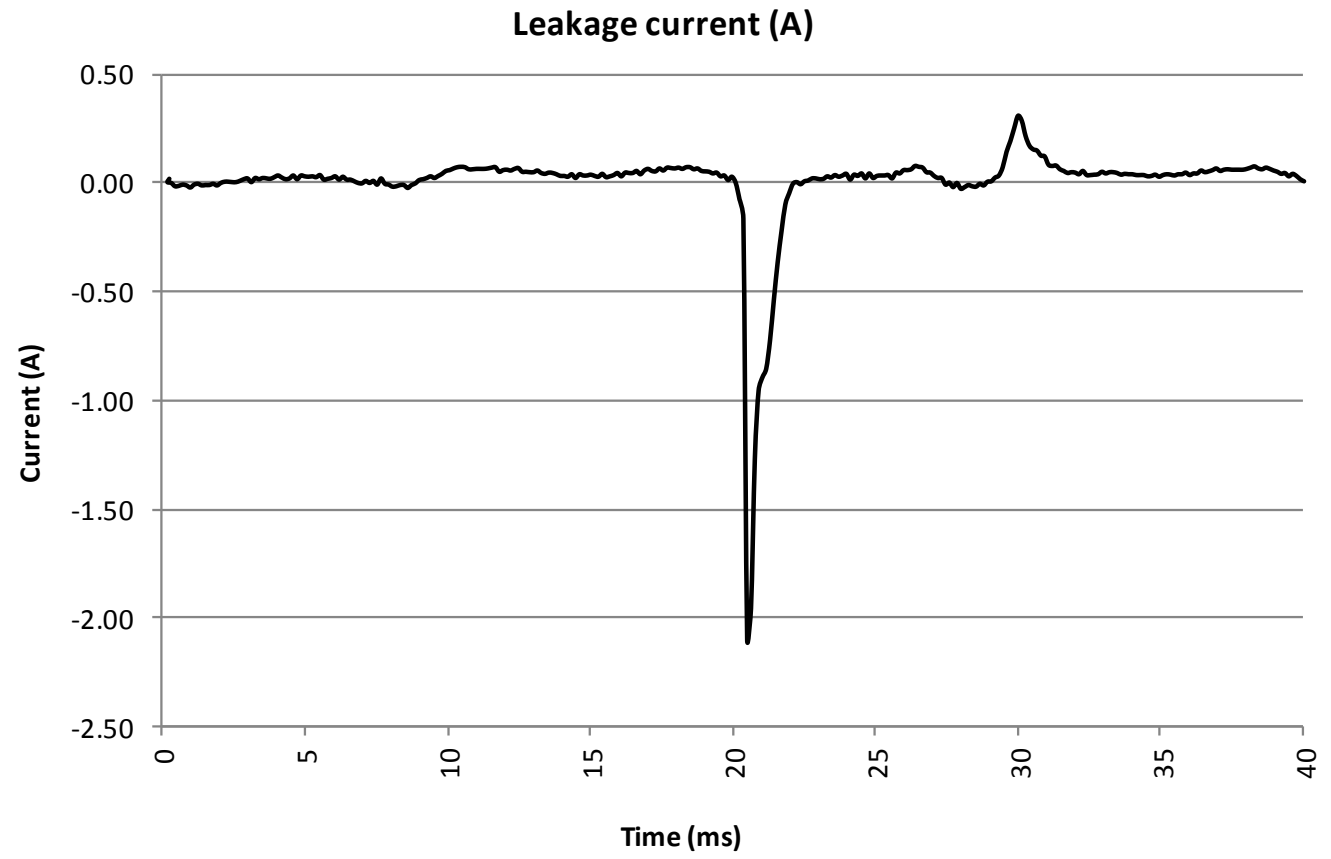

Fig. 3. Leakage current during an RCCB tripping event on the 19/11/2011 at $4.05 \mathrm{pm}$ in circuit A. 
Similar behaviour was recorded in circuit B. Voltage and current recorded measurements during a trip were obtained at $3.54 \mathrm{pm}$ on the $24 / 03$ (Fig. 4).

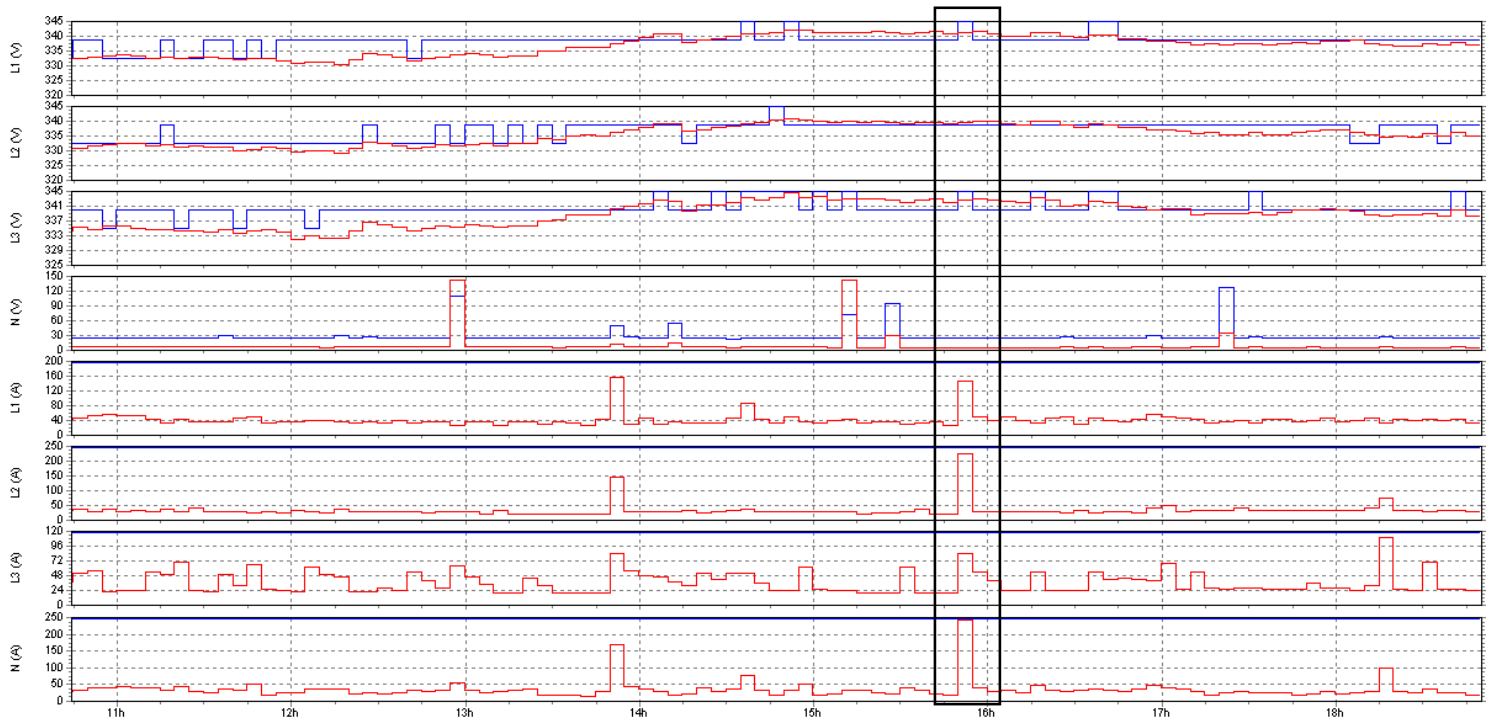

Fig. 4. Voltage and current recording for $24 / 03$ at $3.54 \mathrm{pm}$ on the RCCB tripped in circuit B.

Summarising the results obtained in circuits $A$ and $B$, the phenomena occurring when an RCCB trips are:

- High peak voltages in some phases (amplitude values close to $500 \mathrm{~V}$ were measured versus $325 \mathrm{~V}$ corresponding to a nominal voltage line-neutral of $230 \mathrm{~V}$ ).

- High peak voltages in the neutral voltage to ground.

- Currents in phases reached higher peak values (more than $200 \%$ over normal value currents depending on the value of the phase voltage at the time of the event). These values may also trip the circuit breaker of the circuit.

- Neutral current is increased in the same order values as the phases.

The conclusion of the research led to the detection of transient problems in power supply voltages that proved to be the cause of the RCCB nuisance tripping.

These disturbances produced leakage currents (by capacitive effect and varistor discharges in electronic equipment) and these leakage currents cause AC RCCBs to trip. Since these are short transients, they do not cause the SI RCCBs (an improved type A RCCB) to trip.

The type of loads present in the hospital (such as electronic loads, TV sets, electronic lights, and medical equipment with electronic power suppliers and batteries) contribute to increasing the transient currents which, in turn, raise the neutral-earth voltages and leakage currents, and so increase the frequency of tripping events. 


\section{Tests performed in circuits feeding electronic loads}

Several tests were performed in a laboratory to study the influence of electronic loads in RCCB nuisance tripping. These tests were performed under the Transnational Access to the Flex Power Grid Lab Research Infrastructure at DNV KEMA (a Dutch business and technical consultancy that tests, inspects, certifies, and verifies the energy value chain) under the DERri project and supported by the European Commission under FP7 [9].

Many tests were performed and the specific single-line set-up diagram used for the tests is shown in Fig. 5.

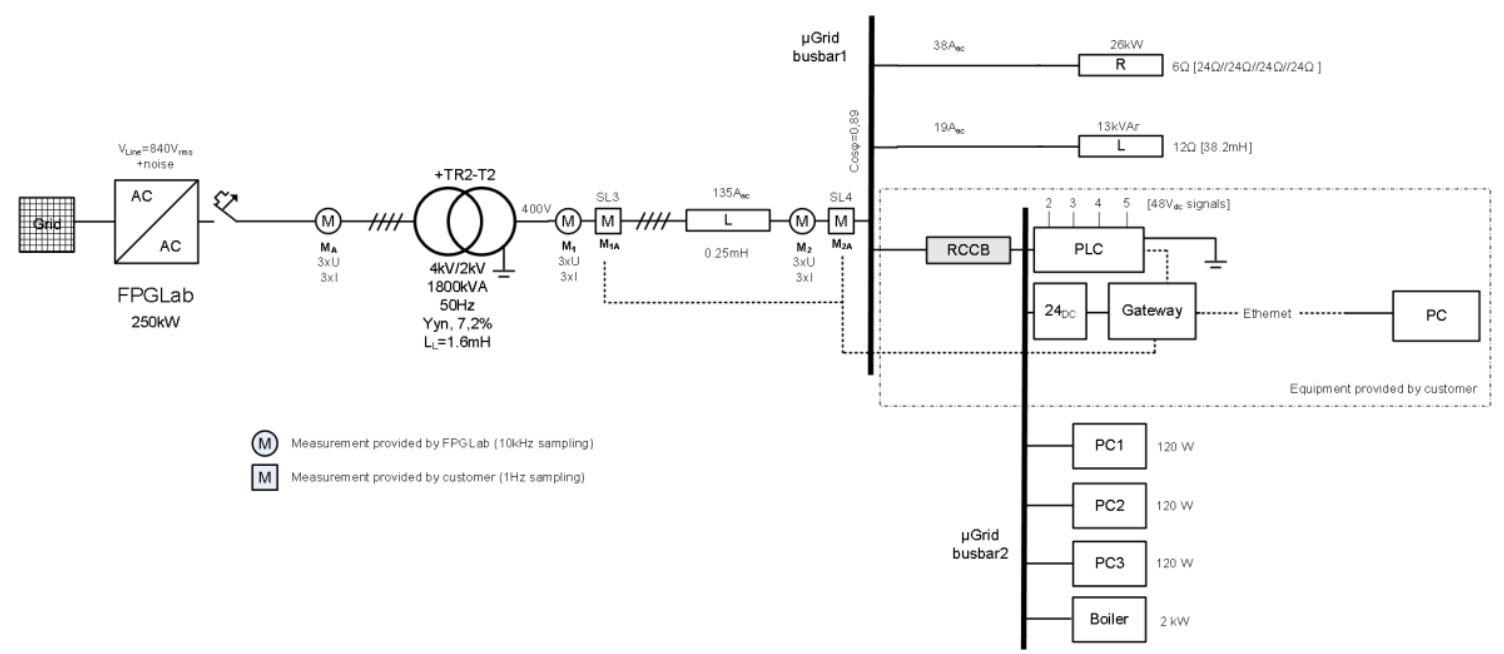

Fig. 5. Test layout for transient analysis in RCCB tripping.

The set-up of the test is prepared from the grid connection to a diverse range of loads. The transformer is earthed. A 250kW AC to AC voltage source (FPGLab) is used to generate the desired voltage waveforms (containing transients). $840 \mathrm{Vrms}$ at the output of the AC voltage source (electrical point $\mathrm{M}_{\mathrm{A}}$ ) are required to obtain $400 \mathrm{Vrms}$ at the electrical point $\mathrm{M}_{1}$. Power meters at different voltage points were installed to record the different waveforms. Three nonlinear loads (computers) were connected downstream of an RCCB 20A 30 mA. Table 1 describes the tests performed. 
Table 1. Description of the tests performed at DNV KEMA.

\begin{tabular}{|l|l|l|}
\hline Number & Description & Label \\
\hline Test 1 & 3 computers ON connected in phase R & (a) \\
\hline Test 2 & 3 computers OFF connected in phase R & (b) \\
\hline Test 3 & 1 boiler ON connected in phase R & (c) \\
\hline Test 4 & 1 computer ON and 1 boiler connected in phase R & (d) \\
\hline
\end{tabular}

The voltages waveforms were the same in all the tests - as shown in the Fig 6.

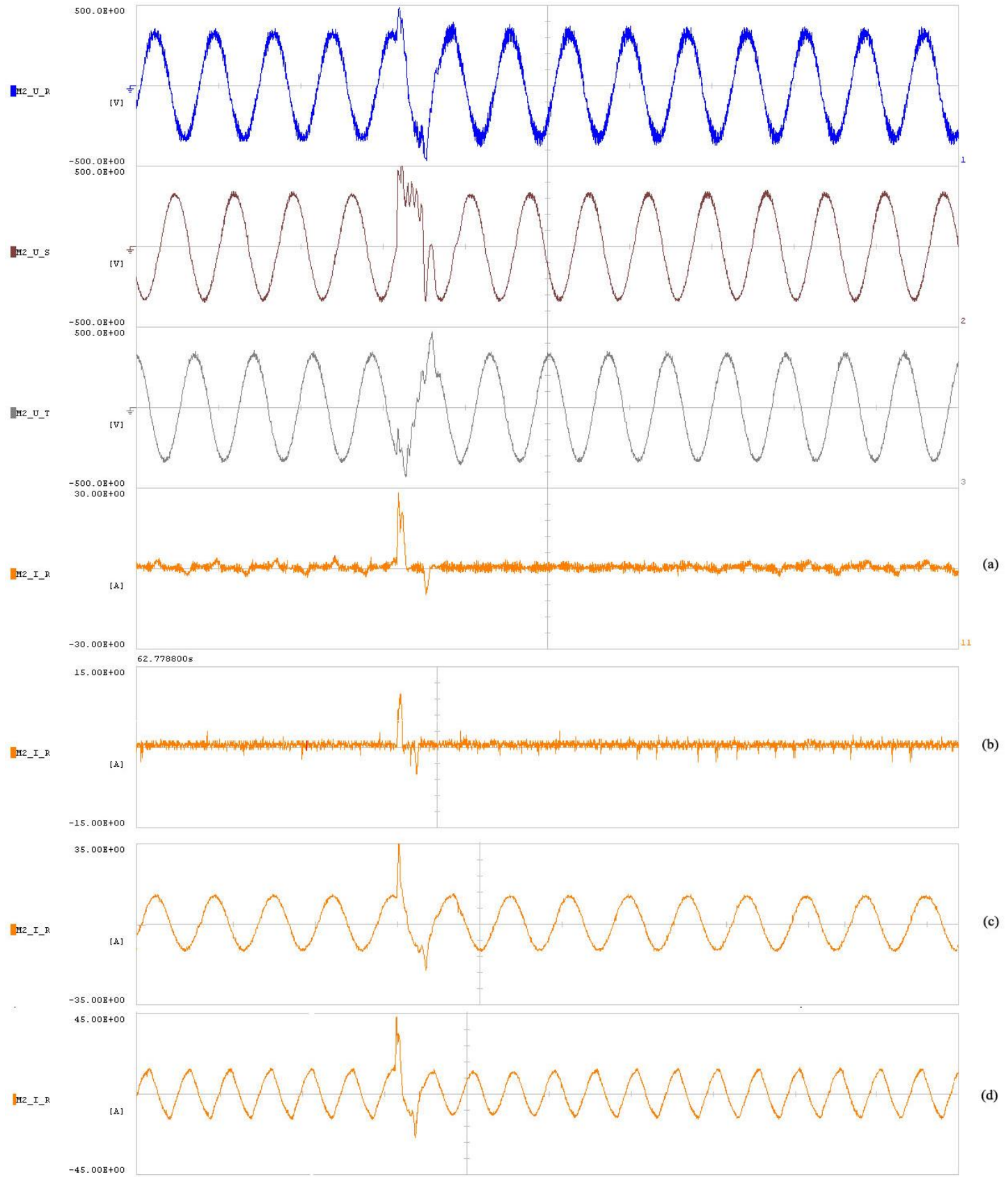

Fig. 6. Waveforms as a response of a perturbation in the voltage supply (x axis: time, $y$ axis: voltages (V) or currents (A)). (a) 3 computers as load (Test 1). (b) 3 unplugged PCs as load (Test 2). (c) Boiler as load (Test 3). (d) Boiler and PC as load (Test 4). 
Test 1 was performed with three computers ON in phase R. Fig. 6 (a) shows that an increase of approximately $1000 \%$ with respect to the nominal current (a value of the amplitude of $2.7 \mathrm{~A}$ changed to $28 \mathrm{~A}$ during the event) is observed in the computer load current (phase $\mathrm{R}$ connection). A similar result is observed when the earth connection is removed from the set-up.

Test 2 was performed connecting three unplugged computers in phase R. Fig. 6 (b) shows that an increase of the current is observed even with the computers are turned off (a value of the amplitude of $0.7 \mathrm{~A}$ changed to $9.8 \mathrm{~A}$ during the event). This may explain why in rooms with many computers, nuisance trips sometimes occur even when the computers are turned off.

In Test 3, a resistive load (a boiler) is connected in phase R. Fig. 6 (c) shows voltage disturbances in circuits feeding resistive loads with current increases of $100 \%$ of the nominal current (a value of the amplitude of 14.2 A changed to $35 \mathrm{~A}$ during the event).

In Test 4, a computer and a resistive load is connected in phase R. Fig. 6 (d) shows that voltage disturbances in circuits feeding resistive loads with electronic loads have current increases greater than those without those electronic loads (a value of the amplitude of $14.7 \mathrm{~A}$ changed to $45 \mathrm{~A}$ during the event).

Additionally, other tests showed that the PC connections have high current transients that even affect the voltage waveform (Fig. 7).

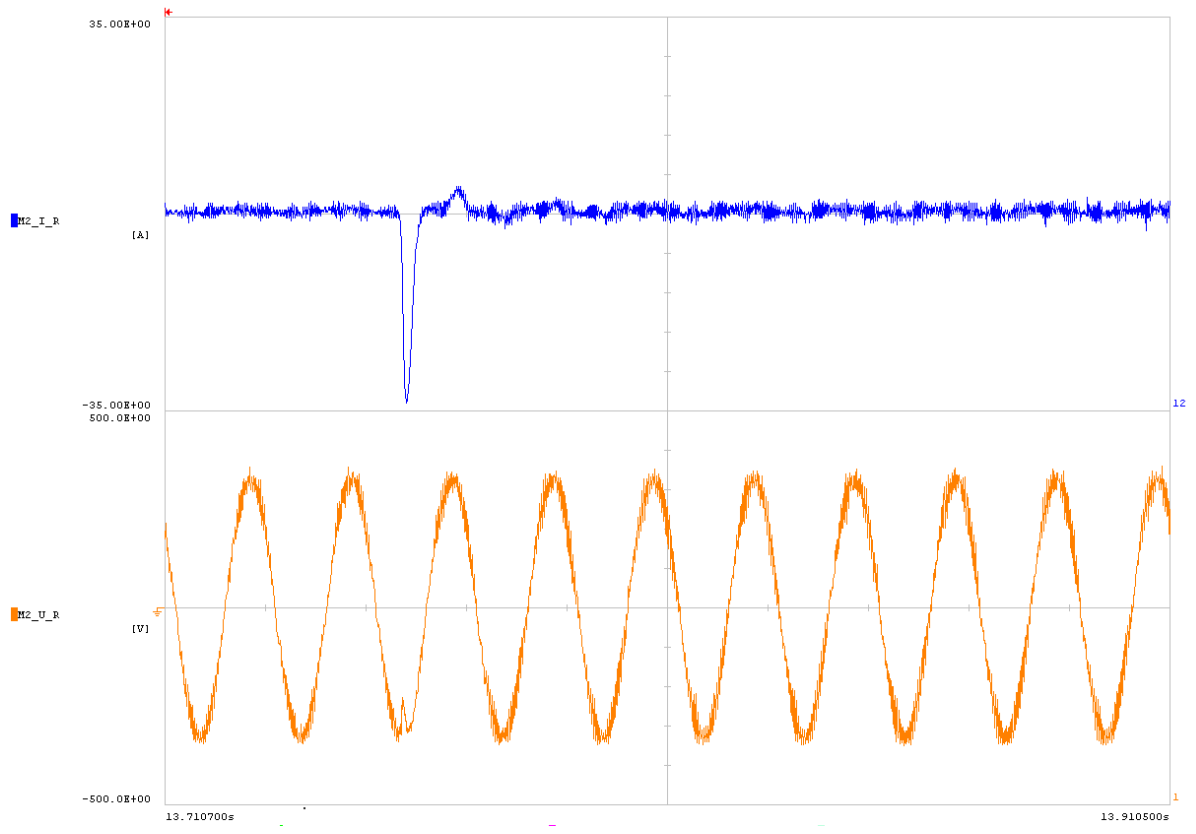

Fig. 7. Current and voltage waveforms as a response to a PC connection. 
In conclusion, non-linear electronic loads (such as computers) have a profound reaction to voltage perturbations/transients. An increase of ten times in the current has been observed during the testing programme. Computers magnify the effect of the transient. This reaction is reduced due to the damping effect of resistance in the load, if the resistive load in the system is increased (relatively less for non-linear loads).

\section{Equivalent circuit for theoretical explanation}

In this section, a simplified equivalent electrical circuit of the data measured in the hospital (Section 2) is presented (Fig. 8) to obtain just the main data related to the phenomenon. The circuit is obtained as an equivalent circuit of a T-T three phase system and uses a Norton equivalent model to represent the nonlinear behaviour of the loads. This circuit enables the authors to further analyse the results and theoretically explain the phenomena.

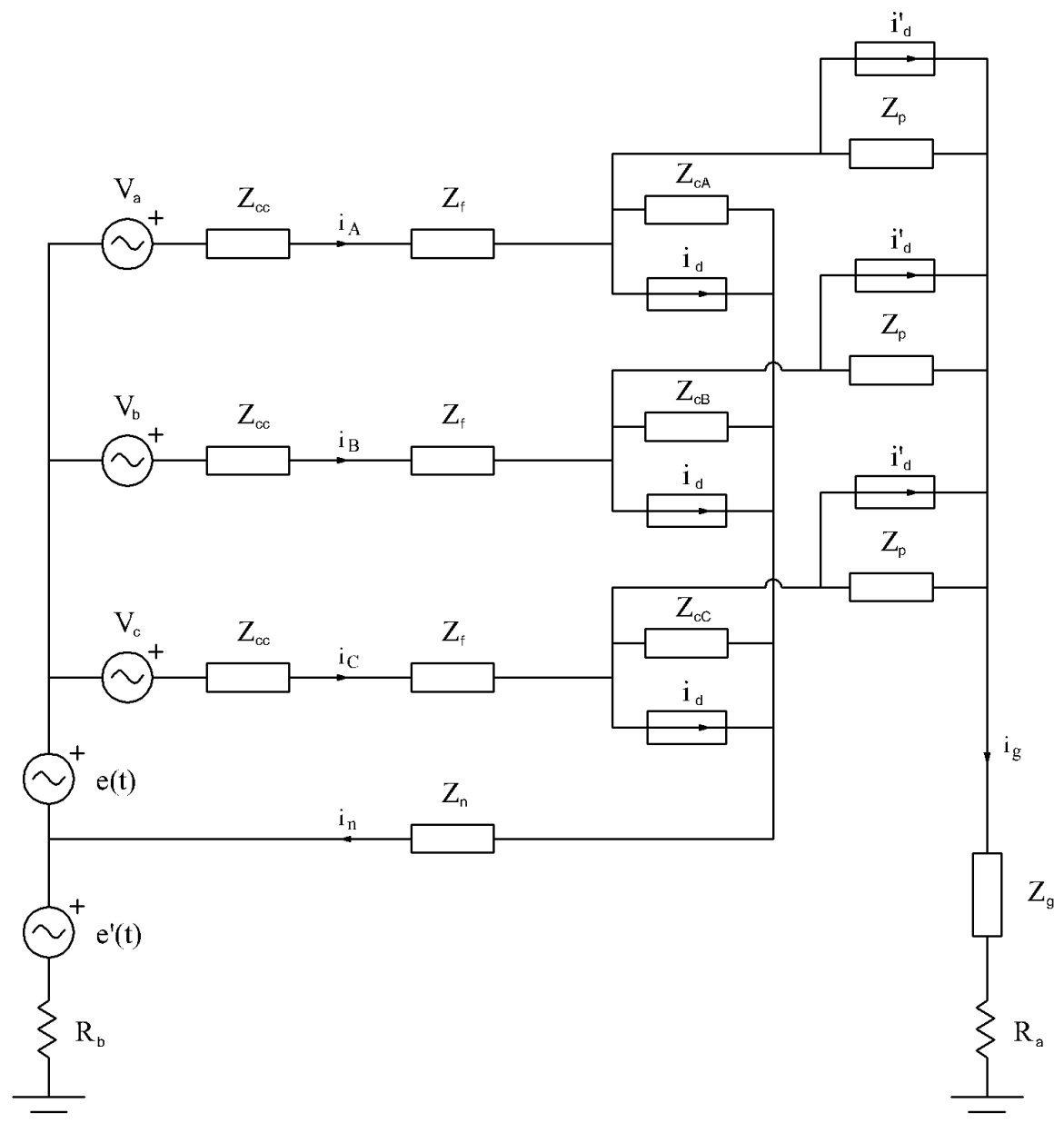

Fig. 8. Equivalent circuit for circuit A.

In the electrical diagram the variables are defined as: 
- $\mathrm{e}^{\prime}(\mathrm{t})$ : disturbance voltage between neutral to earth.

- $\mathrm{e}(\mathrm{t})$ : disturbance voltage between phases to neutral.

- $\mathrm{Z}_{\mathrm{cc}}$ : transformer short circuit impedance.

- $\mathrm{Z}_{\mathrm{f}}$ : phase cable impedance.

$-\mathrm{Z}_{\mathrm{n}}$ : neutral cable impedance.

- $\mathrm{Z}_{\mathrm{cI}}$ : load impedance in phase $\mathrm{I}$.

- $Z_{p}$ : impedance between phases and earth.

- $\mathrm{Z}_{\mathrm{g}}$ : cable impedance to ground protection.

$-\mathrm{R}_{\mathrm{a}}$ : grounding resistance of the mass loads.

- $\mathrm{R}_{\mathrm{b}}$ : grounding resistance of neutral to earth transformer connection.

- $i_{d}(t)$ : current source in the nonlinear loads as a result of a disturbance of the voltage and showing an increase in consumption of the load in response to a disturbance. A Norton equivalent model is used to represent the nonlinear behaviour of the loads.

- $i_{d}^{\prime}(t)$ : current source that represents the capacitive effect and varistors present in the nonlinear loads that forces a discharge current in reaction to a voltage surge using the Norton model. The value is modelled as the expression $\mathrm{i}_{\mathrm{d}}(\mathrm{t})=\alpha \cdot|\mathrm{e}(\mathrm{t})| \cdot[\mathrm{v}(\mathrm{t})+\mathrm{e}(\mathrm{t})]$, for each phase. Values of the parameters used in the model for circuit A are shown in Table 1. Real values are used for the three-phase system and tuned values for the Norton equivalents to obtain results consistent with the measurements presented in Section 2.

Table 1. Values of the different parameters and currents in the equivalent circuit.

\begin{tabular}{|l|l|l|l|l|l|l|l|l|l|l|l|l|}
\hline Variable & $\begin{array}{l}\mathrm{R}_{\mathrm{a}} \\
(\Omega)\end{array}$ & $\begin{array}{l}\mathrm{R}_{\mathrm{b}} \\
(\Omega)\end{array}$ & $\begin{array}{l}\mathrm{e}^{\prime} \\
(\mathrm{V})\end{array}$ & $\begin{array}{l}\mathrm{e} \\
(\mathrm{V})\end{array}$ & $\begin{array}{l}\mathrm{Z}_{\mathrm{CC}} \\
(\Omega)\end{array}$ & $\begin{array}{l}\mathrm{Z}_{\mathrm{f}} \\
(\Omega)\end{array}$ & $\begin{array}{l}\mathrm{Z}_{\mathrm{n}} \\
(\Omega)\end{array}$ & $\begin{array}{l}\mathrm{Z}_{\mathrm{cA}} \\
(\Omega)\end{array}$ & $\begin{array}{l}\mathrm{i}_{\mathrm{d}} \\
(\mathrm{A})\end{array}$ & $\begin{array}{l}\mathrm{Z}_{\mathrm{p}} \\
(\mathrm{k} \Omega)\end{array}$ & $\begin{array}{l}\mathrm{Z}_{\mathrm{g}} \\
(\Omega)\end{array}$ & $\begin{array}{l}\mathrm{i}_{\mathrm{d}}^{\prime} \\
(\mathrm{A})\end{array}$ \\
\hline Value & 1 & 1 & 0 & -150 & 0,0016 & 0,7 & 1 & 180 & 0 & 100 & 10 & -20 \\
\hline
\end{tabular}


In the case analysed $\mathrm{Z}_{\mathrm{cB}}(\Omega)=130$ for phase $\mathrm{B}$, and $\mathrm{Z}_{\mathrm{cC}}(\Omega)=360$ for phase $\mathrm{C}$, because the behaviour of the circuit is not symmetrical. The voltage surge analysed is a zero sequence surge in phase voltages $\left(\mathrm{e}^{\prime}=0 \mathrm{~V}\right)$ and $\alpha$ is tuned to $0.028 \mathrm{~mA} / \mathrm{V}$.

Table 2 presents the values of the currents obtained solving the circuit during the event. Currents obtained in the theoretical circuit are similar to those obtained in the experimental measurements (Fig. 2).

Table 2. Values of the currents in the equivalent circuit during the event.

\begin{tabular}{|l|l|l|l|l|l|}
\hline Variable & $\mathrm{i}_{\mathrm{n}}(\mathrm{A})$ & $\mathrm{i}_{\mathrm{g}}(\mathrm{A})$ & $\mathrm{i}_{\mathrm{A}}(\mathrm{A})$ & $\mathrm{i}_{\mathrm{B}}(\mathrm{A})$ & $\mathrm{i}_{\mathrm{C}}(\mathrm{A})$ \\
\hline Value & -3.74 & -1.89 & -1.29 & -5.23 & -0.88 \\
\hline
\end{tabular}

This model explains all the phenomena in the analysed circuits when a disturbance voltage between phases and neutral and an event occurs:

- Peak voltages are detected in the neutral voltage to ground.

- Currents in phases reached higher peak values (depending on the value of the voltage in each phase at that moment). These values may also trip the circuit breaker.

- Neutral current is increased in the same proportions as the phases.

- Current discharge to earth increases and may force the RCCBs to trip.

Circuits feeding electronic loads in the presence of voltage disturbances suffer current surges magnified by the electronic load power suppliers and this causes the RCCBs to trip (due to capacitive effect and varistor discharges).

The result presented in this paper may enable RCCBs manufacturers to make the necessary changes to avoid nuisance tripping and, electronic component manufacturers to modify designs in order to avoid this behaviour during voltage surges.

On the one hand, the authors propose, in real facilities in use suffering nuisance tripping of RCCBs, to request the utility to improve the power quality of the supply voltage, to install uninterrupted power suppliers (UPS), or to use SI RCCBs in sensitive circuits. On the other hand, the authors propose, in the design stage of facilities with electronic loads, to use a T-N earthing system to avoid installing RCCBs or to use a dedicated line from the transformer centre to supply the sensitive loads. 


\section{Conclusion}

Current in circuits supplying electronic loads presents a high component of harmonics but these are not the cause of nuisance tripping of residual current circuit breakers. Circuits feeding this type of load in situations when there are supply voltage disturbances, suffer current surges magnified by the electronic loads and discharge currents to ground that cause RCCBs to trip. Disturbances produce leakage currents by capacitive effect and varistor discharges in electronic equipment. These leakage currents may cause type $A C$ and type $A$ RCCBs to trip - but short duration transients do not cause immunised RCCBs (SI RCCBs) to trip. Replacement of AC RCCBs by SI RCCBs considerably reduces the problem of nuisance tripping, but also masks the frequent presence of voltage transients and this is likely to shorten the life of the receivers, and may increase the number of failures in these loads.

\section{Acknowledgments}

This research work has been made possible with the support of the Programa de Apoyo a la Investigación y Desarrollo (PAID-06-12) de la Universitat Politècnica de València (Spain), the GV/2015/068-Ayudas para la realización de proyectos de I+D para grupos de investigación emergentes and the Flex Power Grid Lab Research Infrastructure at DNV KEMA, the Netherlands under the European FP7 project - DERri (grant agreement 228449).

\section{References}

[1] C. Roldán-Porta, G. Escrivá-Escrivá, F.J. Cárcel-Carrasco, C. Roldán-Blay, Nuisance tripping of residual current circuit breaker: A practical case. Elect. Power Syst. Res. 106 (2014) $180-187$

[2] I. X. Luo, Y. Du, X. H. Wang, M. L. Chen, Tripping characteristics of residual current devices under nonsinusoidal currents, IEEE T. Ind. Appl. 47 (2011) 1515-1521.

[3] A. C. Liew, Nuisance trippings of residual-current circuit breakers or ground fault protectors of power sources connected to computer and electronic loads, J. Elect. Power Syst. Res. 20 (1990) 23-30. 
[4] Schneider Electric S.A., Residual current operated circuit-breakers without integrated overcurrent protection for household and similar uses (RCCBs) Part 1: General Rules, Tecfoto, Madrid, 2006.

[5] T. M. Lee, T. W. Chan, The effects of harmonics on the operational characteristics of residual-current circuit breakers, Proc. of EMPD ‘95, 2 (1995) 548-553.

[6] A. M. Featherstone, A. S. Sastrosubroto, An examination of RCD performance during system disturbances (and other relays), Safeguarding Industrial Plant during Power System Disturbances, IEE Colloquium on, 3 (1989) 1-6.

[7] Czapp S., The effect of earth fault current harmonics on tripping of residual current devices, Electrical Review, 1 (2009) 196-201.

[8] J. A. Martinez, F. Gonzalez-Molina, Surge protection of underground distribution cables, IEEE T. Power Deliver. 15 (2000) 54-60.

[9] DERri - Distributed Energy Resources Research Infrastructure, http://www.der-ri.net, October 2014. 